\section{A) Check for updates}

Cite this: Inorg. Chem. Front., 2021, 8, 711

Received 2nd November 2020, Accepted 22nd November 2020 DOI: 10.1039/d0qi01303j

rsc.li/frontiers-inorganic

\title{
Aluminium(III) and zinc(II) complexes of azobenzene-containing ligands for ring-opening polymerisation of $\varepsilon$-caprolactone and rac-lactide $\uparrow$
}

\author{
Sandeep Kaler, ${ }^{a}$ Paul McKeown, (DD ${ }^{a}$ Benjamin D. Ward (DD ${ }^{b}$ and \\ Matthew D. Jones (D) *a
}

\begin{abstract}
The ability to control the outcome of polymerisations using an external stimulus remains a formidable challenge. Herein, we report a series of photoactive Schiff base ligands bearing azobenzene moieties, as well as seven Al(III) and $\mathrm{Zn}(I)$ complexes. Trans-cis isomerisation of the ligands and complexes occurred by exposure to UV light. Photoisomerisation was investigated using spectroscopic techniques and realtime reaction monitoring was conducted using FlowNMR. The activity of the complexes was tested in ring-opening polymerisation (ROP) of $\varepsilon$-caprolactone and rac-lactide under ambient and UV light conditions, with the isomers of the $\mathrm{Al}(\mathrm{III})$ complexes displaying marked differences in activity in the ROP of $\varepsilon$-caprolactone.
\end{abstract}

\section{Introduction}

The proliferation of plastic usage since its commercial development in the 1930s has led to increasing concerns regarding its environmental impact. In 2018, 359 million tonnes (MT) of plastic was produced globally, ${ }^{1}$ compared to $1.5 \mathrm{MT}$ in $1950 .^{2}$ Biodegradable polymers are deemed to be a suitable alternative to oil-derived polymers with polylactic acid (PLA), an aliphatic polyester, being one of the most well-known of the renewable polymers. One advantage of PLA, besides being degradable under compostable conditions, is that it can be chemically recycled to form other useful derivatives such as methyl lactate. ${ }^{3}$ Prices of PLA have dropped significantly over the last 20 years which has expanded its use to many areas, including biomedical and packaging applications. ${ }^{4-8}$ Research in this area is becoming highly sophisticated and its continuous evolution is reliant on new highly capable catalytic systems.

The use of an external stimulus such as light, ${ }^{9}$ redox processes, ${ }^{10}$ or mechanical force ${ }^{11}$ to control polymerisations is a very promising area of research. Light has many advantages over other external triggers, such as its non-invasive nature, easy handling, and its ability to exert a high level of control by

\footnotetext{
${ }^{a}$ Department of Chemistry, Univeristy of Bath, Claverton Down, Bath, BA2 7AY, UK. E-mail:Mj205@bath.ac.uk

${ }^{b}$ Department of Chemistry, Cardiff University, Park Place, Cardiff, CF10 3AT, UK $\dagger$ Electronic supplementary information (ESI) available: Full experimental protocols and data. CCDC 2041481-2041486. For ESI and crystallographic data in CIF or other electronic format see DOI: 10.1039/d0qi01303j
}

tuning the wavelength or intensity of the light source. ${ }^{12}$ The use of light to control molecular weight and gain sequence control is therefore highly attractive in the area of polymer chemistry. ${ }^{13}$ Hawker and co-workers have demonstrated the effective use of light in both iridium based and metal-free atom transfer radical polymerisations (ATRP), which operate via a redox equilibrium process. The use of light in the activation and deactivation of the copolymerisation allowed a high level of sequence control as well as accurate control over molecular weight and chain end groups. ${ }^{14}$ However, the main drawback of photoredox catalysis is the need for continuous irradiation to maintain population of the excited states. In contrast, photoswitchable catalysis involves a photochromic moiety being incorporated into the catalyst. This form of light controlled catalysis relies on a difference in activity or selectivity for the "on" and "off" catalytic species. For example, a catalyst in its initial "off" state could proceed slowly, or not at all, and once irradiated with light of an appropriate wavelength it could lead to an increase in activity or selectivity towards a single monomer, allowing incorporation of that monomer into the chain. In order for the catalyst to be effective, a significant geometrical change must be induced upon irradiation, which can result in a cooperative, ${ }^{15,16}$ steric $^{17-19}$ or electronic effect. $^{20,21}$

Azobenzene is one of the most widely used photochromic units for this purpose, ${ }^{22}$ and irradiation of the trans isomer with light of an appropriate wavelength results in trans-cis isomerisation. The reverse cis-trans isomerisation can be induced thermally or by the use of visible light. ${ }^{23-26}$ One of the earliest examples of photoswitchable catalysis based on a confor- 
mational change induced by trans-cis isomerisation of azobenzene was reported by Ueno, Takahashi and Osa in 1981, whereby capping a $\beta$-cyclodextrin with an azobenzene unit allowed modulation of the rate of ester hydrolysis. ${ }^{17}$ In the area of polymer chemistry, Hecht and co-workers have reported a highly robust organocatalyst whose catalytic activity towards ring-opening polymerisation (ROP) of cyclic monomers could be turned on and off by light-induced keto-enol tautomerism. One of the most remarkable aspects of this work was the ability to control the monomer sequence of copolymerisations by a single catalytic system. ${ }^{27}$ Chen et al. demonstrated the use of salicylaldimine $\mathrm{Zn}$ (II) catalysts bearing azobenzene ligands for the ROP of various monomers, with a remarkable 6-fold reactivity difference reported for $\varepsilon$-caprolactone upon irradiation with light. ${ }^{28}$ However, reports of metal catalysts bearing azobenzene units for photocontrolled ROP are generally rare, as most of the photoswitchable catalysis to date has focused on the transformation of small molecules using organocatalysts. ${ }^{16,29,30}$

Herein, we report the successful synthesis of five $\mathrm{Al}(\mathrm{III})$ and two $\mathrm{Zn}$ (II) based complexes bearing ligands containing azobenzene units. The extent of their trans-cis isomerisation has been investigated using UV-Vis absorption spectroscopy, ${ }^{1} \mathrm{H}$ NMR spectroscopy and FlowNMR. The activity of the complexes has been tested in the application of ROP of rac-lactide (LA) and $\varepsilon$-caprolactone ( $\varepsilon$-CL) under ambient and UV light conditions.

\section{Results}

\section{Ligand and complex preparation}

A series of three Schiff-base ligands containing photoactive azobenzene moieties were easily synthesised in high yields of $\sim 90 \%$ by a condensation reaction of the substituted salicylaldehyde and 4-phenyl(diazenyl)aniline (Scheme 1). $1 \mathrm{H}$ has been reported previously by methods similar to those reported here. ${ }^{31-33}$ The formation of the ligands was confirmed by NMR spectroscopy, with primarily ( $>97 \%$ ) trans-azo species being

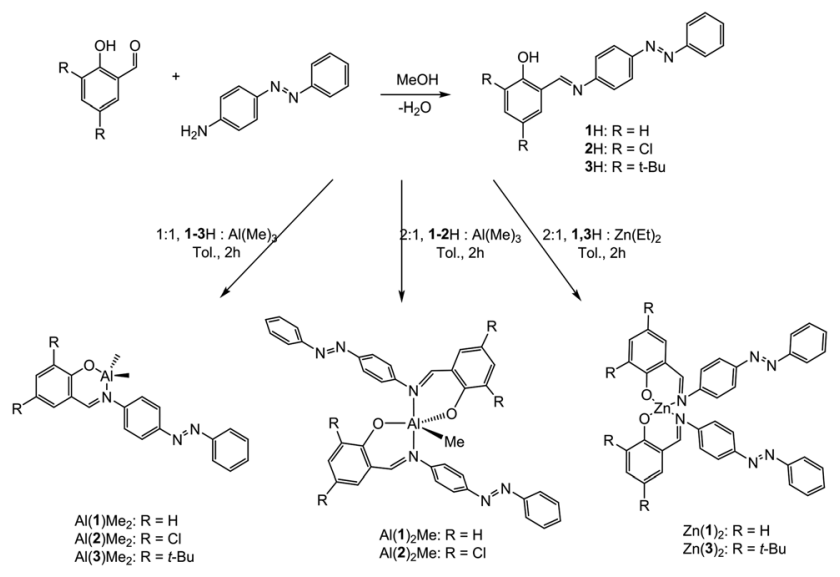

Scheme 1 Preparation of the ligands $1-3 \mathrm{H}$ and $\mathrm{Al}(\mathrm{III})$ and $\mathrm{Zn}(\mathrm{II})$ complexes. present. The ${ }^{1} \mathrm{H}$ NMR spectra of $1-3 \mathrm{H}$ exhibit a sharp singlet resonance in the region $\delta=8.50-8.70 \mathrm{ppm}$, corresponding to imine environments, with the concurrent ${ }^{13} \mathrm{C}\left\{{ }^{1} \mathrm{H}\right\}$ NMR signal at ca. 165 ppm. Subsequently, five Al(III) complexes were successfully prepared by complexation of the pro-ligands $(\mathbf{1}-\mathbf{3 H})$ to $\mathrm{Al}(\mathrm{Me})_{3}$ in a $1: 1$ or $2: 1$ molar ratio $(\mathrm{M}: \mathrm{XH})$ in anhydrous toluene. Solid-state structures of $\mathrm{Al}(\mathrm{III})$ complexes were obtained by single crystal X-ray diffraction (Fig. 1). Elemental analysis for some complexes, particularly $\mathrm{Al}(\mathbf{1}) \mathrm{Me}_{2}$, showed small deviations from the expected values, however further analysis by NMR spectroscopy, along with the solid-state structures confirmed formation of the pure complexes.

Two Zn(II) complexes are reported here by complexation of the pro-ligands with $\mathrm{Zn}(\mathrm{Et})_{2}$ in a procedure similar to the $\mathrm{Al}(\mathrm{III})$ complexes. $\operatorname{Zn}(\mathbf{1})_{2}$ has been reported previously by Markiewicz et al. via a subcomponent self-assembly procedure, where the ligand was not isolated prior to complexation with the metal. ${ }^{31}$ A single crystal suitable for X-ray diffraction of $\mathrm{Zn}(3)_{2}$ was obtained. Following numerous attempts at forming a single crystal of $\mathrm{Zn}(\mathbf{1})_{2}$, the characterisation of $\mathrm{Zn}(\mathbf{1})_{2}$ was based on NMR spectroscopy and elemental analysis, which both supported formation of the complex. Despite numerous attempts, $\mathrm{Al}(3)_{2} \mathrm{Me}$ and $\mathrm{Zn}(2)_{2}$ could not be successfully isolated. ${ }^{1} \mathrm{H}$ NMR spectroscopy of the complexes revealed the imine proton to be upfield shifted with reference to the free ligands. For the $\mathrm{Al}(\mathrm{III})$ complexes, the metal-alkyl signals $\delta=-0.15$ to -0.97 ppm integrated to 3 and 6 for $2: 1$ and $1: 1$ complexes, respectively.

\section{Crystal structure analysis of $\mathrm{Al}(\mathrm{III})$ and $\mathrm{Zn}$ (II) complexes}

$\mathrm{Al}(\mathbf{1}) \mathrm{Me}_{2}$ exhibited a four-coordinate structure with the $\mathrm{Al}(\mathrm{III})$ centre tended towards a tetrahedral geometry and a $\tau_{4}$ index of
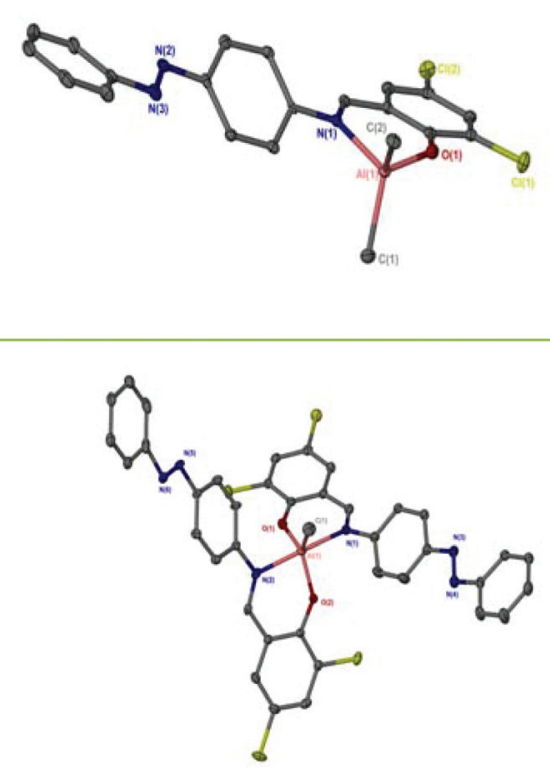

Fig. 1 Solid-state structures of $\mathrm{Al}(2) \mathrm{Me}_{2}$ (top) and $\mathrm{Al}(2)_{2} \mathrm{Me}$ (bottom). Hydrogen atoms have been omitted for clarity. Ellipsoids are shown at $50 \%$ probability level. 
Table 1 Selected bond lengths $(\AA \AA)$ and angles $\left({ }^{\circ}\right)$ for Al complexes Al $(1-3) \mathrm{Me}_{2}$ and $\mathrm{Al}(1-2)_{2} \mathrm{Me}$

\begin{tabular}{llllll}
\hline & $\mathrm{Al}(\mathbf{1}) \mathrm{Me}_{2}$ & $\mathrm{Al}(\mathbf{1})_{2} \mathrm{Me}$ & $\mathrm{Al}(2) \mathrm{Me}_{2}$ & $\mathrm{Al}(2)_{2} \mathrm{Me}$ & $\mathrm{Al}(3) \mathrm{Me}_{2}$ \\
\hline $\mathrm{Al}-\mathrm{O}(1)$ & $1.780(3)$ & $1.775(2)$ & $1.771(5)$ & $1.777(2)$ & $1.779(9)$ \\
$\mathrm{Al}-\mathrm{C}(1)$ & $1.956(4)$ & $1.981(4)$ & $1.969(7)$ & $1.975(3)$ & $1.957(15)$ \\
$\mathrm{Al}-\mathrm{N}(1)$ & $1.979(3)$ & $2.130(3)$ & $1.979(5)$ & $2.138(3)$ & $1.981(11)$ \\
$\mathrm{Al}-\mathrm{N}(2)$ & - & $2.082(3)$ & - & $2.119(3)$ & - \\
$\mathrm{O}(1)-\mathrm{Al}-\mathrm{N}(1)$ & $94.79(12)$ & $86.57(11)$ & $94.8(2)$ & $88.60(10)$ & $93.5(4)$ \\
$\mathrm{N}(1)-\mathrm{Al}-\mathrm{C}(1)$ & $113.13(16)$ & $92.91(13)$ & $108.9(3)$ & $93.37(15)$ & $110.1(5)$ \\
$\mathrm{O}(1)-\mathrm{Al}-\mathrm{C}(1)$ & $111.35(17)$ & $122.37(13)$ & $109.1(3)$ & $123.96(15)$ & $111.9(6)$ \\
$\mathrm{C}(1)-\mathrm{Al}-\mathrm{C}(2)$ & $117.0(2)$ & - & $119.4(3)$ & - & $119.6(7)$ \\
$\mathrm{O}(2)-\mathrm{Al}-\mathrm{N}(1)$ & - & $88.17(10)$ & - & $87.35(10)$ & - \\
$\mathrm{N}(2)-\mathrm{Al}-\mathrm{N}(2)$ & - & 167.84 & - & $173.01(10)$ & - \\
$\tau_{4}$ & 0.92 & - & 0.91 & - & 0.91 \\
$\tau_{5}$ & - & 0.75 & - & 0.82 & -
\end{tabular}

0.9, calculated using Houser's method. ${ }^{34}$ Table 1 summarises selected bond lengths and angles for each of the complexes. The complexes prepared by a $1: 1$ molar ratio have near identical geometries and $\tau_{4}$ values were in agreement with the tetrahedral geometries displayed in the solid-state structures obtained for $\mathrm{Al}(2) \mathrm{Me}_{2}$ and $\mathrm{Al}(3) \mathrm{Me}_{2}\left(\tau_{4}=0.9\right.$ in both cases). The complexes prepared by a $2: 1$ molar ratio were penta-coordinate and the calculated $\tau_{5}$ values for $\mathrm{Al}(\mathbf{1}-2)_{2} \mathrm{Me}$ demonstrate a distorted trigonal bipyramidal geometry, with the perfect trigonal bipyramidal index being equal to $1 .^{35}$ The solid statestructure of $\mathrm{Zn}(3)_{2}$ revealed a four-coordinate complex with a $\tau_{4}$ value of 0.9 suggestive of a distorted tetrahedral geometry (Table 2, Fig. 2).

Table 2 Selected bond lengths $(\AA \AA)$ and angles $\left(^{\circ}\right)$ for $\mathrm{Zn}(3)_{2}$

\begin{tabular}{ll}
\hline & $\mathrm{Zn}(3)_{2}$ \\
\hline $\mathrm{N}(1)-\mathrm{Zn}$ & $1.996(3)$ \\
$\mathrm{N}(2)-\mathrm{Zn}$ & $1.983(3)$ \\
$\mathrm{O}(1)-\mathrm{Zn}$ & $1.903(3)$ \\
$\mathrm{O}(2)-\mathrm{Zn}$ & $1.983(3)$ \\
$\mathrm{O}(1)-\mathrm{Zn}-\mathrm{N}(2)$ & $121.01(12)$ \\
$\mathrm{O}(1)-\mathrm{Zn}-\mathrm{N}(1)$ & $117.81(11)$ \\
$\mathrm{O}(1)-\mathrm{Zn}-\mathrm{N}(1)$ & $95.14(12)$ \\
$\mathrm{N}(1)-\mathrm{Zn}-\mathrm{N}(2)$ & $109.82(13)$ \\
$\tau_{4}$ & 0.9
\end{tabular}

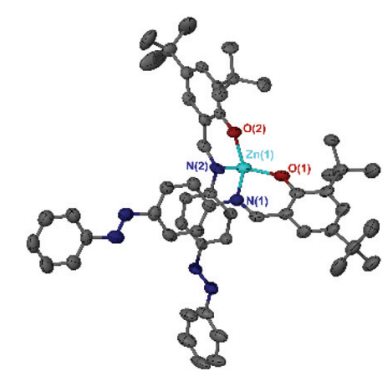

Fig. 2 Solid-state structure of $\mathrm{Zn}(3)_{2}$. Hydrogen atoms have been omitted for clarity. Ellipsoids are shown at 50\% probability level.

\section{Photoisomerisation behaviour of the ligands and complexes}

The photoisomerisation behaviour of the ligands and complexes was studied initially by UV-Vis and ${ }^{1} \mathrm{H}$ NMR spectroscopies. The UV-Vis absorption spectra of a $\mathrm{CHCl}_{3}$ solution of the free ligand $\mathbf{1 H}$ displayed a maximum absorption at around $365 \mathrm{~nm}$ corresponding to the $\pi-\pi^{*}$ transition $(\varepsilon \sim 14400 \mathrm{~L}$ $\mathrm{mol}^{-1} \mathrm{~cm}^{-1}$ ) of the trans isomer and a weaker band at around $500 \mathrm{~nm}\left(\varepsilon \sim 750 \mathrm{~L} \mathrm{~mol}^{-1} \mathrm{~cm}^{-1}\right)$ due to the $n-\pi^{*}$ transition of the cis azobenzene unit (Fig. 3). ${ }^{22}$ Irradiation with $365 \mathrm{~nm}$ light led to a decrease in the absorbance of the $\pi-\pi^{*}$ band and an increase in the $n-\pi^{*}$ band, accompanied by a colour change. The ${ }^{1} \mathrm{H}$ NMR spectrum of $1 \mathrm{H}$ prior to irradiation exhibited a set of imine signals which supported formation of $97 \%$ trans isomer in solution. Upon irradiation of the $\mathrm{CDCl}_{3}$ solutions in an NMR tube with $365 \mathrm{~nm}$ light, a set of new signals became progressively apparent in the aromatic region of the spectrum, corresponding to cis-1H (Fig. 4). Trans-cis iso-

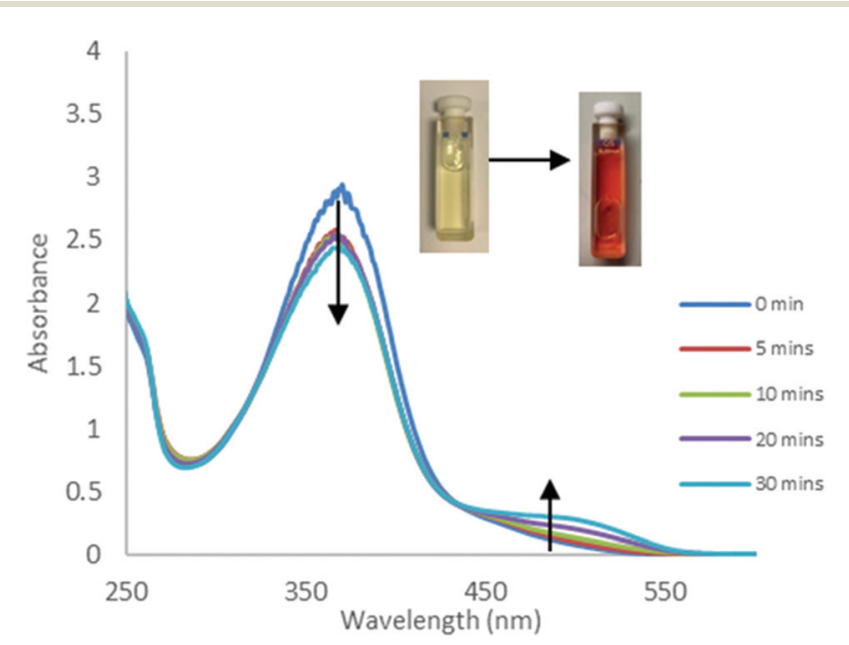

Fig. 3 UV-Vis absorption spectra obtained during UV irradiation (365 nm) of $1 \mathrm{H}$ in $\mathrm{CHCl}_{3}\left(\mathrm{C}=2 \times 10^{-4} \mathrm{M}\right)$ at various time intervals.

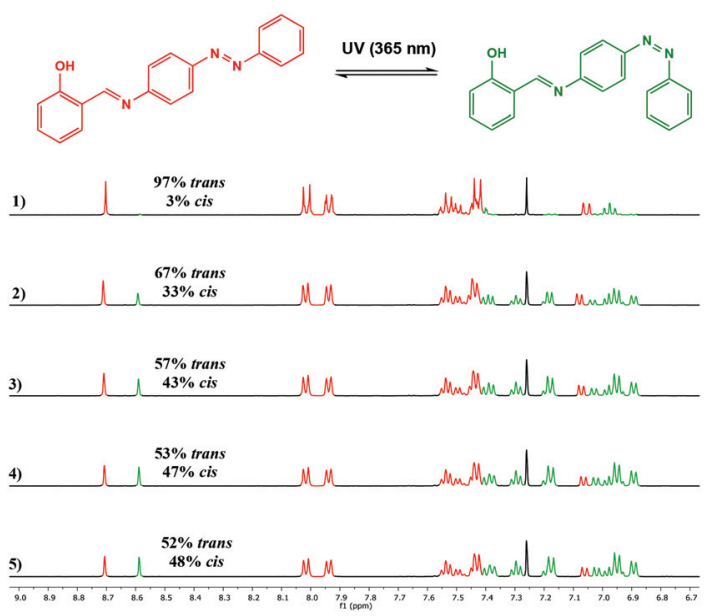

Fig. $4{ }^{1} \mathrm{H}$ NMR spectrum $\left(500 \mathrm{MHz} \mathrm{CDCl}_{3}\right)$ of $1 \mathrm{H}$ showing spectral changes during UV irradiation: (1) prior to irradiation; (2) after 5 min; (3) after $10 \mathrm{~min}$; (4) after $20 \mathrm{~min}$ and (5) after $30 \mathrm{~min}$. 
merisation could be quantified by integration of the imine signal. The original signal at $\delta=8.71 \mathrm{ppm}$ decreased in intensity, whilst a signal at $\delta=8.59 \mathrm{ppm}$ increased. After 30 minutes of irradiation a photostationary state (PSS) was reached with a mixture of $48 \%$ cis and $52 \%$ trans isomers present. $2 \mathrm{H}$ and $3 \mathrm{H}$ also demonstrated photoresponsive behaviour when exposed to UV light (ESI Fig. 21†). Of all the ligands synthesised $1 \mathrm{H}$ contained the highest abundance of cis isomer at the PSS.

Photoisomerisation of the complexes was studied in a similar manner to the ligands to investigate the effects of complexation to $\mathrm{Al}(\mathrm{III})$ and $\mathrm{Zn}$ (II) on the extent of cis isomer formation. UV-Vis absorption spectra of $\mathrm{Al}(\mathbf{1}) \mathrm{Me}_{2}$ revealed a hypsochromic shift of the maximum absorption to around $340 \mathrm{~nm}\left(\varepsilon \sim 12500 \mathrm{~L} \mathrm{~mol}^{-1} \mathrm{~cm}^{-1}\right)$ (Fig. 5). Upon irradiation with UV light, the $\pi-\pi^{*}$ transition was observed to decrease as a function of time. ${ }^{1} \mathrm{H}$ NMR spectroscopy was used to further support this by irradiation of $\mathrm{C}_{6} \mathrm{D}_{6}$ sample within an NMR tube. The spectrum for $\mathrm{Al}(2) \mathrm{Me}_{2}$ displayed a sharp singlet for the expected aluminium alkyl signal at $\delta=-0.27 \mathrm{ppm}$, which could be assigned to the trans configuration, with $4 \%$ cis isomer detected at $\delta=-0.37 \mathrm{ppm}$ (Fig. 6). Upon irradiation, the signal at $\delta=-0.37 \mathrm{ppm}$ increased in intensity suggestive of increasing formation of cis- $\mathrm{Al}(2) \mathrm{Me}_{2}$. A set of new resonances in the aromatic region could also be observed and integration of the signals indicated the presence of two species with identical numbers of protons. In comparison, ${ }^{1} \mathrm{H}$ NMR spectra of the complexes $\mathrm{Al}(\mathbf{1}-\mathbf{2})_{2} \mathrm{Me}$ showed singlets relating to three possible configurations due to the presence of two ligand arms on the metal centre. For example, the spectrum for $\mathrm{Al}(2)_{2} \mathrm{Me}$ (Fig. 7) suggested a mixture of two isomers present in solution prior to irradiation, with the azobenzene units in either the trans-trans or trans-cis configuration. Spectral changes across the whole ${ }^{1} \mathrm{H}$ NMR spectrum could be observed upon irradiation; however, the most easily quantifiable change was observed in the intensities of the Al-Me signals. A third signal

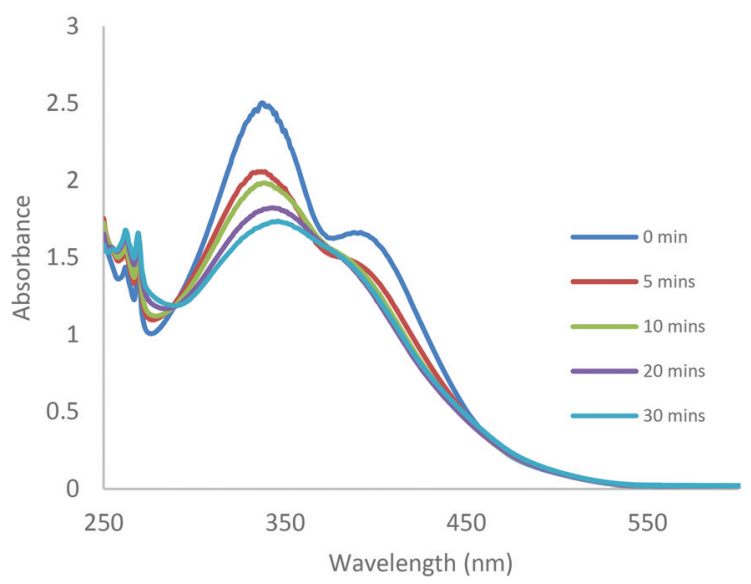

Fig. 5 UV-Vis absorption spectra obtained during UV irradiation of $\mathrm{Al}(\mathbf{1})$ $\mathrm{Me}_{2}$ in $\mathrm{CDCl}_{3}\left(C=2 \times 10^{-4} \mathrm{M}\right)$ at various time intervals.

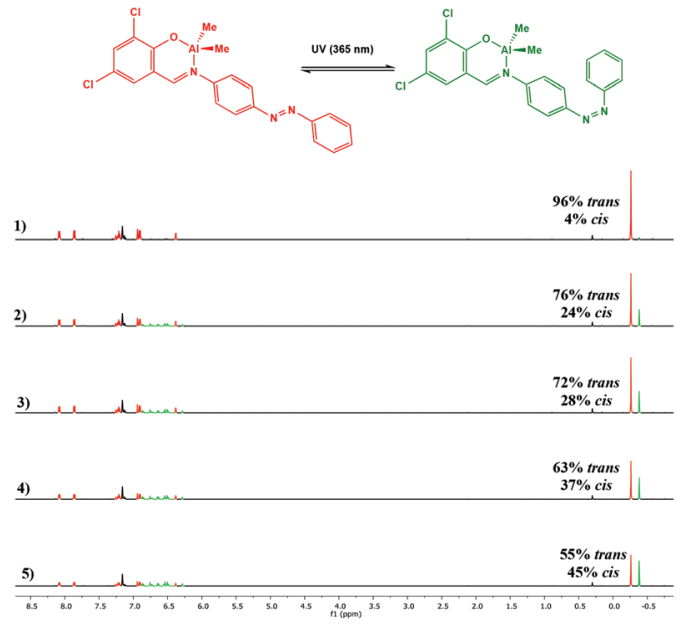

Fig. $6{ }^{1} \mathrm{H}$ NMR spectrum $\left(500 \mathrm{MHz}, \mathrm{C}_{6} \mathrm{D}_{6}\right)$ of $\mathrm{Al}(2) \mathrm{Me}_{2}$ showing spectral changes during UV irradiation: (1) prior to irradiation; (2) after 5 min; (3) after $10 \mathrm{~min}$; (4) after $20 \mathrm{~min}$ (5) after $30 \mathrm{~min}$.

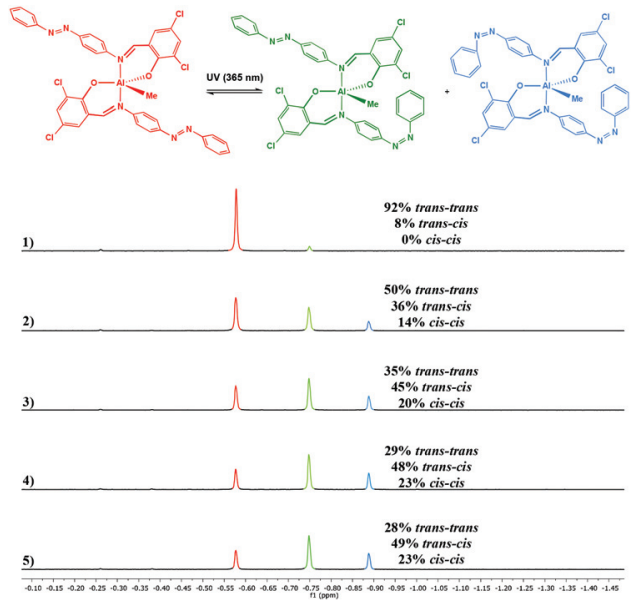

Fig. $7{ }^{1} \mathrm{H}$ NMR spectrum $\left(500 \mathrm{MHz}_{2} \mathrm{CDCl}_{3}\right)$ of $\mathrm{Al}(2)_{2} \mathrm{Me}$ showing spectral changes during UV irradiation: (1) prior to irradiation; (2) after 5 min; (3) after $10 \mathrm{~min}$; (4) after $20 \mathrm{~min}$ and (5) after $30 \mathrm{~min}$.

of increasing intensity appeared upfield with increasing irradiation, indicating formation of the cis-cis isomer.

$\mathrm{Zn}$ (II) complexes, $\mathrm{Zn}(\mathbf{1}, \mathbf{3})_{2}$, also exhibited trans-cis isomerisation upon exposure to UV light, with the clearest spectral changes observed for the imine signal. An increase in irradiation time resulted in four well-separated resonances corresponding to the imine protons (Fig. 8). The signal furthest downfield corresponded to both ligand arms in the transtrans configuration. A further signal upfield to the major trans isomer was assigned to a ligand in the trans configuration, with a further peak of identical intensity slightly upfield being attributed to the neighbouring ligand in the cis configuration. Finally, the signal furthest upfield was that of the imine protons in the cis-cis configuration. Similar to results obtained by Markiewicz et al., we observed that the extent of photoisomerisation of the $\mathrm{Zn}$ (II) complexes was in closest agreement 

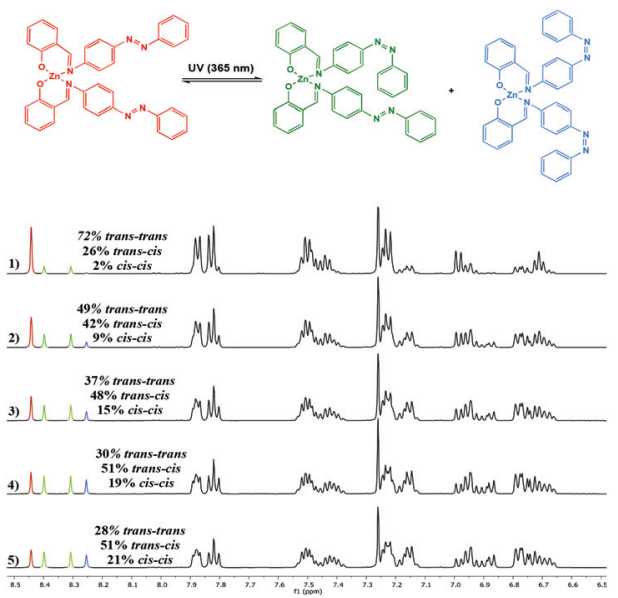

Fig. $8{ }^{1} \mathrm{H}$ NMR spectrum $\left(500 \mathrm{MHz}, \mathrm{C}_{6} \mathrm{D}_{6}\right)$ of $\mathrm{Zn}(1)_{2}$ showing spectral changes during UV irradiation: (1) prior to irradiation; (2) after $5 \mathrm{~min}$; (3) after $10 \mathrm{~min}$; (4) after $20 \mathrm{~min}$ (5) after $30 \mathrm{~min}$.

with the free ligand, compared to the $\mathrm{Al}(\mathrm{III})$ complexes, with nearly $40 \%$ cis-cis isomer present in $\mathrm{Zn}(3)_{2} \cdot{ }^{31}$ The thermal cistrans isomerisation was also investigated by heating a solution of sample $\mathrm{Al}(2) \mathrm{Me}_{2}$ which had been irradiated for $30 \mathrm{~min}\left(\lambda_{\max }\right.$ $=365 \mathrm{~nm}$ ) to reach a PSS. The sample was heated at $80^{\circ} \mathrm{C}$ for one hour and monitored via ${ }^{1} \mathrm{H}$ NMR spectroscopy. The ${ }^{1} \mathrm{H}$ NMR spectrum after heat treatment resulted in restoration of the original signals prior to irradiation with no cis isomer detected at this point and no photodecomposition of the complexes was detected.

Photoisomerisation investigations of the ligands and complexes was further complimented by FlowNMR which allows monitoring of the catalytic species in real-time and is especially useful for identification of changes in photochemical reactions. ${ }^{36}$ On-line FlowNMR studies were carried out by continuous irradiation of the reaction vessel containing a solution of the complex which was flowed into the NMR spectrometer. Monitoring the reaction in continuous flow allowed ${ }^{1} \mathrm{H}$ NMR measurements to be recorded every 60 seconds, however a two- fold delay in reaching a PSS was noted, presumably due to the quantity of the solution in the flow tube not being illuminated (Fig. 9 and 10). The change in concentration of the trans and cis isomers could be easily calculated from integration of the imine signals from each spectrum obtained (ESI Fig. 36 and $37 \dagger$ ). The results obtained were in good agreement with the static NMR experiments. Fig. 11 shows a kinetics plot of the trans-cis isomerisation in $\mathrm{Al}(3) \mathrm{Me}_{2}$ fitted from results obtained by FlowNMR experiments. The rate of change of concentration of trans isomer to form cis isomer indicates firstorder kinetics with a rate constant of $k_{\mathrm{TC}}=2.09 \times 10^{-2} \mathrm{~min}^{-1}$.

\section{Photo-controlled ring-opening polymerisation}

Following investigation of the photoswitching capabilities of the free ligands and their complexes, we envisaged that they could be tested as initiators in the ROP of rac-LA and $\varepsilon$-CL, with the aim of controlling the outcome of the reactions using

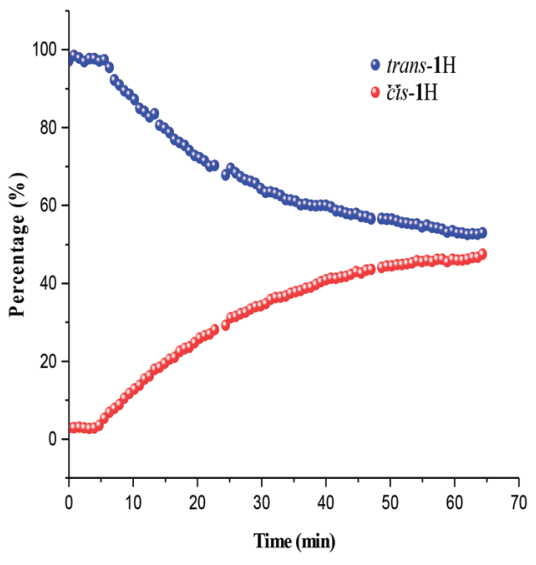

Fig. 9 Trans-cis isomerisation of ligand $1 \mathrm{H}$ calculated from FlowNMR spectroscopy.

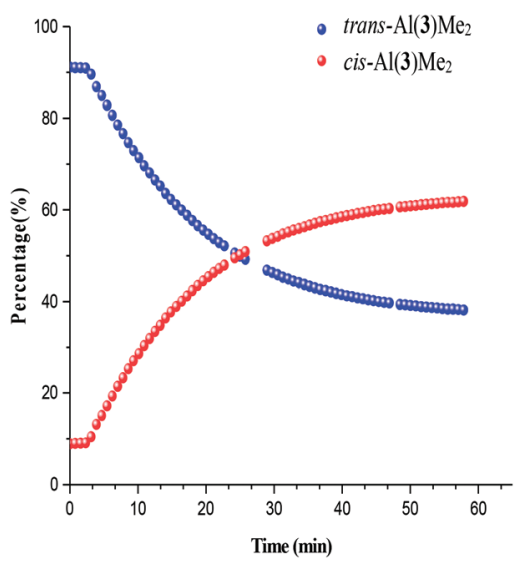

Fig. 10 Trans-cis isomerisation of $\mathrm{Al}(3) \mathrm{Me}_{2}$. Note: blanks in data due to spectrometer shimming.

light to exert some steric and electronic effects around the metal centre. The polymerisations of rac-LA were conducted in anhydrous toluene at $80{ }^{\circ} \mathrm{C}$ for $4 \mathrm{~h}$, and monitored by ${ }^{1} \mathrm{H}$ NMR spectroscopy, whereby the conversion was calculated by analysis of the methine region. Generally, the $\mathrm{Al}(\mathrm{III})$ dimethyl complexes, $\mathrm{Al}(1-3) \mathrm{Me}_{2}$, displayed superior activity compared to their monomethyl counterparts, for example a comparison of $\mathrm{Al}(\mathbf{1}) \mathrm{Me}_{2}$ and $\mathrm{Al}(\mathbf{1})_{2} \mathrm{Me}$ displayed a two-fold increase in activity. Increasing steric congestion around the $\mathrm{Al}(\mathrm{III})$ centre with the presence of two ligand arms could affect coordination of the monomer, making it less favourable. The effect of modifying the substituents on the ligand also appeared to play a role in the activity of the complexes. The increasing steric bulk on the phenoxy moiety resulted in lower conversions, with the tertbutyl substituted $\mathrm{Al}(3) \mathrm{Me}_{2}$ achieving a conversion of $18 \%$ (Table 3, entry 9). Modification of the two $\mathrm{R}$ groups effects both the accessibility and Lewis acidity of the metal centre, with bulky tert-butyl electron donating groups resulting in a sterically hindered and less Lewis acidic $\mathrm{Al}(\mathrm{III})$ centre. The $\mathrm{Zn}$ (II) complexes displayed a similar pattern with regards to 


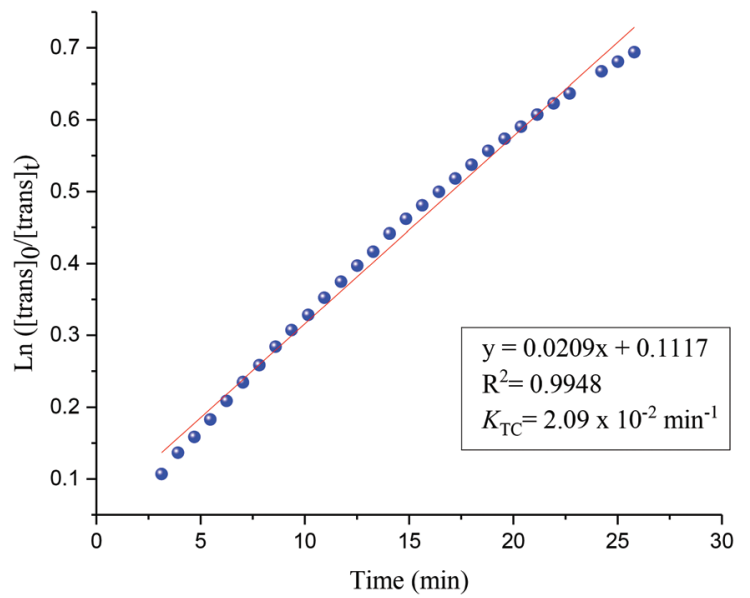

Fig. 11 First-order plot for trans-cis isomerisation (UV = $365 \mathrm{~nm}$ ) fitted with results obtained from FlowNMR. [trans $]_{0}=0.0123 \mathrm{~mol} \mathrm{dm}^{-3}$.

activity to the $\mathrm{Al}$ (III) complexes, however the disparity between activities achieved was less pronounced upon switching from a $\mathrm{H}$-substituted phenoxy fragment to a more sterically hindered one (Table 4).

All PLA samples were analysed by GPC and demonstrated moderate number average molecular weights and narrow dispersities (1.10-1.42), indicating a controlled polymerisation process. The tacticity of the polymers produced was analysed using homonuclear decoupled ${ }^{1} \mathrm{H}$ NMR and all initiators were atactic $\left(P_{\mathrm{r}} c a\right.$. 0.5). End group determination was carried out using MALDI-ToF (ESI Fig. 32 and $33 \dagger$ ) and confirmed the polymers bear $-\mathrm{H}$ and $-\mathrm{OBn}$ end groups. Two series were observed with a repeating unit of $72 \mathrm{Da}$, indicating some transesterification. Upon switching to UV light, a third minor series was also observed, particularly in the low mass region with no end groups, suggesting formation of some cyclic oligomers under UV irradiation. The polymerisations conducted under UV conditions were carried out under continuous in situ irradiation to maintain population of the excited states and prevent reverse cis-trans isomerisation. Similar activities were observed for the rac-LA monomer under ambient and UV light conditions, with the activities remaining near identical. This could be explained by the application of heat which could facilitate the reverse isomerisation from the meta-stable cis isomer to the more thermodynamically favourable trans isomer. Generally, good $M_{\mathrm{n}}$ control was still observed under UV conditions and narrow dispersity values were retained. Following this, we attempted to alter the reaction conditions to eliminate the requirement for heat, and so a second series of experiments were conducted in $\mathrm{CH}_{2} \mathrm{Cl}_{2}$ at room temperature, however the $\mathrm{Al}(\mathrm{III})$ complexes were inactive under these conditions. Since several aluminium based complexes have been reported for the ROP of $\varepsilon$-CL, ${ }^{37-40}$ we postulated that the complexes prepared here could effectively catalyse the ROP of $\varepsilon$-CL, with the added benefit of using light to exert a higher degree of control where required. The ROP experiments of $\varepsilon$-CL were carried out at room temperature in anhydrous toluene (Table 5). All Al(III) complexes were active toward the ROP of $\varepsilon$-CL, however complexes $\mathrm{Al}(\mathbf{1}-\mathbf{3}) \mathrm{Me}_{2}$ displayed superior activities under these conditions. $\mathrm{Al}(2) \mathrm{Me}_{2}$ afforded the highest

Table 3 ROP of rac-LA initiated by $\mathrm{Al}\left(\right.$ III) complexes under ambient and UV light conditions ${ }^{a}$

\begin{tabular}{|c|c|c|c|c|c|c|c|}
\hline Entry & Initiator & Conv. ${ }^{b} \%$ & $M_{\mathrm{nGPC}}{ }^{c}$ & $M_{\text {ntheo }}{ }^{d}$ & $\bigoplus^{c}$ & $P_{\mathrm{r}}^{e}$ & Light \\
\hline 1 & $\operatorname{Al}(\mathbf{1}) \mathrm{Me}_{2}$ & 92 & 9450 & 13369 & 1.17 & 0.42 & Ambient \\
\hline 2 & $\mathrm{Al}(\mathbf{1}) \mathrm{Me}_{2}$ & 85 & 11850 & 12360 & 1.34 & 0.44 & UV \\
\hline 3 & $\mathrm{Al}(\mathbf{1})_{2} \mathrm{Me}$ & 45 & 10100 & 6593 & 1.10 & 0.42 & Ambient \\
\hline 4 & $\mathrm{Al}(\mathbf{1})_{2} \mathrm{Me}$ & 45 & 7700 & 6593 & 1.12 & 0.43 & UV \\
\hline 5 & $\mathrm{Al}(2) \mathrm{Me}_{2}$ & 80 & 13550 & 11639 & 1.12 & 0.47 & Ambient \\
\hline 6 & $\mathrm{Al}(2) \mathrm{Me}_{2}$ & 80 & 4100 & 11639 & 1.11 & 0.48 & UV \\
\hline 7 & $\mathrm{Al}(2)_{2} \mathrm{Me}$ & 72 & 6950 & 10486 & 1.10 & 0.45 & Ambient \\
\hline 8 & $\mathrm{Al}(2)_{2} \mathrm{Me}$ & 71 & 11800 & 10342 & 1.10 & 0.44 & UV \\
\hline 9 & $\mathrm{Al}(3) \mathrm{Me}_{2}$ & 18 & 1300 & 2702 & 1.15 & 0.43 & Ambient \\
\hline 10 & $\operatorname{Al}(3) \mathrm{Me}_{2}$ & 31 & 5200 & 4576 & 1.12 & 0.42 & UV \\
\hline
\end{tabular}

${ }^{a}$ General conditions: toluene $(10 \mathrm{~mL}), 100: 1: 1\{[\mathrm{LA}] /[\mathrm{Cat}] /.[\mathrm{I}]\}, 80{ }^{\circ} \mathrm{C} / 4 \mathrm{~h} .{ }^{b}$ Obtained from ${ }^{1} \mathrm{H}$ NMR analysis. ${ }^{c}$ Determined via $\mathrm{GPC}$ analysis in THF. ${ }^{d} M_{\mathrm{n}, \text { theo }}=\left\{M_{\mathrm{w}}(\right.$ lactide $) \times$ conv. $\left.(\%)+M_{\mathrm{w}}(\mathrm{BnOH})\right\} .{ }^{e}$ Determined via homonuclear decoupled NMR spectroscopy.

Table 4 ROP of rac-LA initiated by Zn(II) complexes under ambient and UV light conditions ${ }^{a}$

\begin{tabular}{|c|c|c|c|c|c|c|c|}
\hline Entry. & Initiator & $\begin{array}{l}\text { Conv. } \\
(\%)^{b}\end{array}$ & $M_{\mathrm{n}, \mathrm{GPC}}{ }^{c}$ & $M_{\mathrm{n}, \text { theo }}{ }^{d}$ & $\bigoplus^{c}$ & $P_{\mathrm{r}}^{e}$ & Light \\
\hline 1 & $\operatorname{Zn}(\mathbf{1})_{2}$ & 78 & 10650 & 11351 & 1.18 & 0.40 & Ambient \\
\hline 4 & $\mathrm{Zn}(3)_{2}$ & 74 & 7750 & 10774 & 1.13 & 0.49 & UV \\
\hline
\end{tabular}

${ }^{a}$ General conditions: toluene $(10 \mathrm{~mL}), 100: 1: 1$ ([LA]/[Cat]/[I] $), 80{ }^{\circ} \mathrm{C} / 4 \mathrm{~h} .{ }^{b}$ Obtained from ${ }^{1} \mathrm{H}$ NMR analysis. ${ }^{c}$ Determined via GPC analysis in THF. ${ }^{d} M_{\mathrm{n}}$, theo $=\left\{\left(M_{\mathrm{w}}(\mathrm{rac}-\mathrm{LA}) \times\right.\right.$ conv. $\left.(\%)+M_{\mathrm{w}}(\mathrm{BnOH})\right\} .{ }^{e}$ Determined via homonuclear decoupled NMR spectroscopy. 
Table 5 ROP of $\varepsilon-\mathrm{CL}$ initiated by $\mathrm{Al}(\mathrm{III})$ complexes $\mathrm{Al}(1-3) \mathrm{Me}_{2}$ under ambient and light conditions ${ }^{a}$

\begin{tabular}{lllllll}
\hline Entry & Initiator & Conv. $^{b}(\%)$ & $M_{\text {n,GPC }}{ }^{c}$ & $M_{\text {n,theo }}{ }^{d}$ & $\Xi^{c}$ & Light \\
\hline 1 & $\mathrm{Al}(\mathbf{1}) \mathrm{Me}_{2}$ & 33 & 8000 & 3874 & 1.17 & Ambient \\
2 & $\mathrm{Al}(\mathbf{1}) \mathrm{Me}_{2}$ & 56 & 13100 & 6500 & 1.20 & UV \\
3 & $\mathrm{Al}(\mathbf{1})_{2} \mathrm{Me}$ & 11 & $\mathrm{ND}$ & 1363 & $\mathrm{ND}$ & Ambient \\
4 & $\mathrm{Al}(\mathbf{1})_{2} \mathrm{Me}$ & 19 & $\mathrm{ND}$ & 2276 & $\mathrm{ND}$ & UV \\
5 & $\mathrm{Al}(2) \mathrm{Me}_{2}$ & 75 & 21350 & 8668 & 1.23 & Ambient \\
6 & $\mathrm{Al}(2) \mathrm{Me}_{2}$ & 97 & 22200 & 11179 & 1.27 & UV \\
7 & $\mathrm{Al}(2)_{2} \mathrm{Me}$ & 47 & 8900 & 5472 & 1.10 & Ambient \\
8 & $\mathrm{Al}(2)_{2} \mathrm{Me}$ & 59 & 16700 & 6842 & 1.10 & UV \\
9 & $\mathrm{Al}(3) \mathrm{Me}_{2}$ & 57 & 7650 & 6614 & 1.12 & Ambient \\
10 & $\mathrm{Al}(3) \mathrm{Me}_{2}$ & 65 & 13900 & 7527 & 1.15 & UV
\end{tabular}

${ }^{a}$ General conditions: toluene $(10 \mathrm{~mL}), 100: 1: 1$ ([ع-CL]/[Cat.]/[I] $)$, rt/ 12 h. ${ }^{b}$ Obtained from ${ }^{1} \mathrm{H}$ NMR analysis. ${ }^{c}$ Determined via GPC analysis in THF. ${ }^{d} M_{\mathrm{n}, \text { theo }}=\left\{\left(M_{\mathrm{w}}(\varepsilon-\mathrm{CL}) \times\right.\right.$ conv. $(\%)+M_{\mathrm{w}}(\mathrm{BnOH})$. GPC values not obtained for entries 3 and 4 due to low conversions. ND, not determined.

conversions (Table 5, entry 5), presumably due to the presence of electron withdrawing groups present on the phenoxy unit of the ligand. All PCL samples (exception Table 5, entries 3 and 4) were analysed by GPC and afforded narrow dispersity values (1.10-1.27), however experimental $M_{\mathrm{n}}$ values were marginally higher than those calculated, indicating the possibility of a higher concentration of inactive initiator present. Switching the polymerisations to UV conditions presented some exciting results with higher activities under UV radiation. For example, polymerisations initiated by $\mathrm{Al}(2) \mathrm{Me}_{2}$ under UV light afforded near quantitative conversion compared to the same experiment under ambient light (Table 5, entries 5 and 6). It is also worth noting that a series of $\varepsilon$-CL polymerisations were also conducted at $80{ }^{\circ} \mathrm{C}$ to determine whether the thermal cis-trans isomerisation prevented any distinct differences in activity between polymerisations conducted under varying light conditions, however at $80{ }^{\circ} \mathrm{C}$ the reactions went to completion in $<15$ minutes, preventing any meaningful comparison between UV and ambient light conditions. For example, an $\varepsilon$-CL polymerisation with $\mathrm{Al}(2)$ $\mathrm{Me}_{2}$ for 15 minutes afforded $100 \%$ conversion $\left(M_{n}=26800 \mathrm{~g}\right.$ $\left.\mathrm{mol}^{-1}, D=1.34\right)$. The MALDI-ToF spectrum of PCL obtained under ambient and UV light (Fig. ESI 34 and S35†) confirmed the polymer to be -OBn and - $\mathrm{H}$ group capped. A single series of peaks was observed, separated by intervals of 114 Da, corresponding to the repeating unit mass. The polymerisation activities of the complexes probably originate from a mixture of steric and electronic effects, dependent upon substitution of the ligand and the monomer being polymerised. A steric effect seemed to be dominating for rac-LA polymerisations, whereas the complexes bearing electron withdrawing groups $\left[\mathrm{Al}(2) \mathrm{Me}_{2}\right.$ and $\left.\mathrm{Al}(2)_{2} \mathrm{Me}\right]$ displayed superior activity in ROP of $\varepsilon$-CL.

\section{Conclusions}

In summary, we have successfully demonstrated the photoswitching behaviour of a range of azobenzene containing ligands with varying substituents, and subsequently their
$\mathrm{Al}(\mathrm{III})$ and $\mathrm{Zn}$ (II) complexes. The extent of cis isomerisation formation was altered depending on the substitution of the ligands. The aluminium complex $\mathrm{Al}(\mathbf{1}) \mathrm{Me}_{2}$ exhibited a lower abundance of cis isomer, compared to its free ligand, however a reverse trend was observed for $\mathrm{Al}(3) \mathrm{Me}_{2}$ and $\mathrm{Al}(2) \mathrm{Me}_{2}$, where an enhancement in trans-cis isomerisation was observed. The photoswitching of the complexes was exploited in the ROP of rac-LA and $\varepsilon$-CL. There were no distinguishable differences in activity for rac-LA polymerisation upon switching from ambient to UV light conditions. The application of heat during polymerisations of rac-LA is believed to play a role in this, however further investigation is required. For $\varepsilon$-CL, a clear increase in catalytic activity was observed upon trans-cis isomerisation under UV light with up to $23 \%$ increase in conversion observed. The switching in activity using light described herein should allow for the selective incorporation of monomers under variable light conditions, and therefore allow access to polymers with varying structures. Further challenges will include the careful design of highly active initiators towards ROP that also offer highly efficient and quantitative conversion during trans-cis isomerisation.

\section{Conflicts of interest}

The authors declare no conflict of interest.

\section{Acknowledgements}

We would like to thank the EPSRC for funding a PhD studentship to SK (EP/L016443/1) and for funding for PM (EP/ $\mathrm{P} 016405 / 1)$. The University of Bath and $\mathrm{MC}^{2}$ are acknowledged for their use of facilities, including FlowNMR (EP/P001475/1). We also thank Alejandro Bara-Estaún and Dr Uli Hintermair for useful discussions regarding FlowNMR measurements.

\section{References}

1 Plastics-the Facts 2019, https:/www.plasticseurope.org/ application/files/1115/7236/4388/FINAL_web_version_Plastics_ the_facts2019_14102019.pdf, (accessed 25 March 2020).

2 World Plastics Production 1950-2015, https://committee. iso.org/files/live/sites/tc61/files/The Plastic Industry Berlin Aug 2016 - Copy.pdf, (accessed 25 March 2020).

3 L. A. Román-Ramírez, P. Mckeown, M. D. Jones and J. Wood, Poly(lactic acid) Degradation into Methyl Lactate Catalyzed by a Well-Defined Zn(II) Complex, ACS Catal., 2019, 9, 409-416.

4 V. Siracusa, P. Rocculi, S. Romani and M. D. Rosa, Biodegradable polymers for food packaging: a review, Trends Food Sci. Technol., 2008, 19, 634-643.

5 I. Manavitehrani, A. Fathi, H. Badr, S. Daly, A. N. Shirazi and F. Dehghani, Biomedical Applications of Biodegradable Polyester, Polymers, 2016, 8, 20. 
6 Y. Lu and S. C. Chen, Micro and nano-fabrication of biodegradable polymers for drug delivery, Adv. Drug Delivery Rev., 2004, 56, 1621-1633.

7 A. Ammala, Biodegradable polymers as encapsulation materials for cosmetics and personal care markets, Int. J. Cosmet. Sci., 2013, 35, 113-124.

8 W. Amass, A. Amass and B. Tighe, A review of biodegradable polymers: Uses, current developments in the synthesis and characterization of biodegradable polyesters, blends of biodegradable polymers and recent advances in biodegradation studies, Polym. Int., 1998, 47, 89-144.

9 S. Shankar, M. Peters, K. Steinborn, B. Krahwinkel, F. D. Sönnichsen, D. Grote, W. Sander, T. Lohmiller, O. Rüdiger and R. Herges, Light-controlled switching of the spin state of iron(III), Nat. Commun., 2018, 9, 4750.

10 C. Chen, Redox-Controlled Polymerization and Copolymerization, ACS Catal., 2018, 8, 5506-5514.

11 A. Piermattei, S. Karthikeyan and R. P. Sijbesma, Activating catalysts with mechanical force, Nat. Chem., 2009, 1, 133137.

12 B. M. Neilson and C. W. Bielawski, Illuminating Photoswitchable Catalysis, ACS Catal., 2013, 3, 1874-1885.

13 B. P. Fors and C. J. Hawker, Control of a Living Radical Polymerization of Methacrylates by Light, Angew. Chem., Int. Ed., 2012, 51, 8850-8853.

14 N. J. Treat, H. Sprafke, J. W. Kramer, P. G. Clark, B. E. Barton, J. Read de Alaniz, B. P. Fors and C. J. Hawker, Metal-Free Atom Transfer Radical Polymerization, J. Am. Chem. Soc., 2014, 136, 16096-16101.

15 R. Cacciapaglia, S. Di Stefano and L. Mandolini, The bisbarium complex of a butterfly crown ether as a phototunable supramolecular catalyst, J. Am. Chem. Soc., 2003, 125, 2224-2227.

16 F. Würthner and J. Rebek, Light-switchable catalysis in synthetic receptors, Angew. Chem., Int. Ed., 1995, 34, 446-448.

17 A. Ueno, K. Takahashi and T. Osa, Photocontrol of catalytic activity of capped cyclodextrin, J. Chem. Soc., Chem. Commun., 1981, 94.

18 H. Sugimoto, T. Kimura and S. Inoue, Photoresponsive molecular switch to control chemical fixation of $\mathrm{CO}_{2}, \mathrm{~J}$. Am. Chem. Soc., 1999, 121, 2325-2326.

19 L. Osorio-Planes, C. Rodríguez-Escrich and M. A. Pericàs, Photoswitchable Thioureas for the external manipulation of catalytic activity, Org. Lett., 2014, 16, 1704-1707.

20 D. Wilson and N. R. Branda, Turning "On" and "Off” a pyridoxal 5'-Phosphate mimic using light, Angew. Chem., Int. Ed., 2012, 51, 5431-5434.

21 B. M. Neilson and C. W. Bielawski, Photoswitchable Organocatalysis: Using Light To Modulate the Catalytic Activities of N-Heterocyclic Carbenes, J. Am. Chem. Soc., 2012, 134, 12693-12699.

22 H. M. D. Bandara and S. C. Burdette, Photoisomerization in different classes of azobenzene, Chem. Soc. Rev., 2012, 41, 1809-1825.

23 G. S. Hartley, The cis-form of azobenzene, Nature, 1937, 140, 281-281.
$24 \mathrm{H}$. Rau and E. Lueddecke, On the Rotation-Inversion Controversy on Photoisomerization of Azobenzenes. Experimental Proof of Inversion, J. Am. Chem. Soc., 1982, 104, 1616-1620.

25 C. R. Crecca and A. E. Roitberg, Theoretical study of the isomerization mechanism of azobenzene and disubstituted azobenzene derivatives, J. Phys. Chem. A, 2006, 110, 81888203.

26 V. Blanco, D. A. Leigh and V. Marcos, Artificial switchable catalysts, Chem. Soc. Rev., 2015, 44, 5341-5370.

27 F. Eisenreich, M. Kathan, A. Dallmann, S. P. Ihrig, T. Schwaar, B. M. Schmidt and S. Hecht, A photoswitchable catalyst system for remote-controlled (co)polymerization in situ, Nat. Catal., 2018, 1, 516-522.

28 M. Li, P. Zhang and C. Chen, Light-Controlled Switchable Ring Opening Polymerization, Macromolecules, 2019, 52, 5646-5651.

29 T. Imahori, R. Yamaguchi and S. Kurihara, AzobenzeneTethered Bis(Trityl Alcohol) as a Photoswitchable Cooperative Acid Catalyst for Morita-Baylis-Hillman Reactions, Chem. - Eur. J., 2012, 18, 10802-10807.

30 M. Samanta, V. S. R. Krishna and S. Bandyopadhyay, A photoresponsive glycosidase mimic, Chem. Commun., 2014, 50, 10577.

31 G. Markiewicz, A. Walczak, F. Perlitius, M. Piasecka, J. M. Harrowfield and A. R. Stefankiewicz, Photoswitchable transition metal complexes with azobenzene-functionalized imine-based ligands: structural and kinetic analysis, Dalton Trans., 2018, 47, 14254-14262.

32 L. Fan, L. Wu and M. Ke, Synthesis of novel phenylazo-substituted salicylaldimine-based boron difluoride complexes, J. Chem. Res., 2015, 39, 442-444.

33 S. Suganya and S. Velmathi, Simple azo-based salicylaldimine as colorimetric and fluorescent probe for detecting anions in semi-aqueous medium, J. Mol. Recognit., 2013, 26, 259-267.

34 L. Yang, D. R. Powell and R. P. Houser, Structural variation in copper(I) complexes with pyridylmethylamide ligands: structural analysis with a new four-coordinate geometry index, tau(4), Dalton Trans., 2007, 955-964.

35 A. W. Addison, T. N. Rao, J. Reedijk, J. van Rijn and G. C. Verschoor, Synthesis, structure, and spectroscopic properties of copper(II) compounds containing nitrogensulphur donor ligands; the crystal and molecular structure of aqua[1,7-bis( $N$-methylbenzimidazol-2'-yl)-2,6-dithiaheptane]copper(II) perchlorate, J. Chem. Soc., Dalton Trans., 1984, 1349-1356.

36 A. M. R. Hall, R. Broomfield-Tagg, M. Camilleri, D. R. Carbery, A. Codina, D. T. E. Whittaker, S. Coombes, J. P. Lowe and U. Hintermair, Online monitoring of a photocatalytic reaction by real-time high resolution FlowNMR spectroscopy, Chem. Commun., 2018, 54, 30-33.

37 C.-T. Chen, C.-A. Huang and B.-H. Huang, Aluminium metal complexes supported by amine bis-phenolate ligands as catalysts for ring-opening polymerization of epsiloncaprolactone, Dalton Trans., 2003, 3799-3803. 
38 W. Yao, Y. Mu, A. Gao, Q. Su, Y. Liu and Y. Zhang, Efficient ring-opening polymerization of epsilon-caprolactone using anilido-imine-aluminum complexes in the presence of benzyl alcohol, Polymer, 2008, 49, 24862491.

39 N. Nomura, T. Aoyama, R. Ishii and T. Kondo, Salicylaldimine-aluminum complexes for the facile and efficient ring-opening polymerization of epsilon-caprolactone, Macromolecules, 2005, 38, 5363-5366.

40 L. Qin, Y. Zhang, J. Chao, J. Cheng and X. Chen, Four- and five-coordinate aluminum complexes supported by $\mathrm{N}, \mathrm{O}-$ bidentate beta-pyrazylenolate ligands: synthesis, structure and application in ROP of epsilon-caprolactone and lactide, Dalton Trans., 2019, 48, 12315-12325. 